\title{
Health seeking behaviour and its determinants among rural population: a cross sectional study in South India
}

\author{
Hemant Kumar, Sachidananda Kapinakadu*, Manjula Anil
}

\begin{abstract}
Department of Community Medicine, A. J. Institute of Medical Sciences and Research Centre, Mangalore, Karnataka, India
\end{abstract}

Received: 13 September 2019

Accepted: 10 October 2019

\section{*Correspondence:}

Dr. Sachidananda Kapinakadu,

E-mail: chinmaysachi@gmail.com

Copyright: (C) the author(s), publisher and licensee Medip Academy. This is an open-access article distributed under the terms of the Creative Commons Attribution Non-Commercial License, which permits unrestricted non-commercial use, distribution, and reproduction in any medium, provided the original work is properly cited.

\begin{abstract}
Background: Remedial action that a person takes to treat his or her perceived illnesses, is called health-seeking behaviour. Understanding health seeking behaviour (HSB) in a community and the factors which influence their decision, are crucial for planning a "need based" comprehensive health care programmes for the people, especially for underprovided and rural population. The objective of present study was to determine HSB and its determinants in a defined rural population.

Methods: A community based cross -sectional study was conducted in rural field practice area of A. J. Institute of Medical Sciences and Research Centre, Mangalore (Karnataka) from 1st October 2017 to 31st July 2018. A total of 866 heads of households were included in the study, using universal sampling method. A pre-tested, validated questionnaire was used to collect the data. p values of $<0.05$ were considered significant.

Results: Among 866 participants, almost all (98.03\%) heads of families were males, while majority of them (35.68 $\%$ ) were farmers. Further, majority $(48.15 \%)$ of the households preferred to visit government hospitals for their ailments, while among those visiting private practitioners, majority of them (55.54\%) preferred Allopath system of medicine. Health insurance subscription rates were found to be low (18.93\%). Main determinants of HSB were observed to be cost of treatment, convenience of approach, quality of services and life threatening emergencies.

Conclusions: Present study brings out higher utilization of government health care facilities among the study subjects, while cost of treatment and life threatening emergencies were the main predictors of HSB.
\end{abstract}

Keywords: Health seeking behaviour, Determinants, Health insurance, Rural

\section{INTRODUCTION}

Health seeking behaviour (HSB) has been defined as any action undertaken by the individuals, who perceive themselves to have a health problem or to be ill, for the purpose of finding an appropriate remedy. ${ }^{1}$ In addition to Allopathic medicine, India has the unique distinction of having six more recognized systems of medicine and these are Ayurveda, Yoga and Naturopathy, Unani, Siddha and Homeopathy (AYUSH). ${ }^{2}$ The acceptance of particular system of medicine differs from urban to rural area, type of disease to be treated, age of the patient and individual perceptions. Understanding of HSB is essential to provide need based health care services to the community. Further, in almost all the developing countries public and the private health sector co-exist, but private health care providers are usually preferred, which may be due to better quality of services and personalised attention; while public health care facilities are given second preference owing to its perceived low quality of treatment, long queues and inadequate facilities. ${ }^{3}$

Despite improvements in access to health care in India, inequalities related to socioeconomic status, geography and gender continue to exist. This is further compounded 
by high out-of-pocket expenditures (OOP), which has been pushing many families below poverty line. A recent study published in "The Lancet" estimated about 39 million people in our country fall into poverty every year as a result of OOP expenditure on health care. ${ }^{4}$ Data from National Health Account published by union Health Ministry reveals that medicines are the biggest financial burden on Indian households. It is estimated that more than 3 lakh crore rupees were spent on health care in $2016-17$, by the households OOP, while $42 \%$ of it went in buying medicines only. In rural India, health care faces a crisis unmatched to any other social sector. Nearly $86 \%$ of the medical visits in India are made by the rural people with majority still travelling more than $100 \mathrm{~km}$ to avail health care facility, of which $70-80 \%$ are OOP expenditure. $^{5}$

In recent years, several developing countries have introduced tax-financed health insurance coverage to their poor populations. India too, joined this effort in 2008 by launching the 'Rashtriya Swasthya Bima Yojana' (RSBY) to protect poor Indian households from financial risks associated with hospitalization expenses. Later in 2018, this scheme was modified and re-named as "Ayushman Bharat" and is aimed at targeting 107.4 million 'poor and vulnerable' families or at least 500 million individuals i.e., about $40 \%$ of India's population. ${ }^{6}$ Studies on health care seeking behaviour of people are essential to plan their "need based" health care services. Although hospital based data is the main stay of information regarding the disease pattern and treatment options exercised by the people, community based studies significantly contribute in planning health care services for the local populations residing a defined geographical areas. $^{7}$

The present study was undertaken to determine HSB and identify various factors which influence the process of decision making, in a defined rural population in Mangalore, Karnataka.

\section{METHODS}

A community based, cross sectional, observational study was undertaken in the rural field practice area of A. J. Institute of Medical Sciences and Research Centre, Mangalore, Karnataka (India), from 1st October 2017 to 31st July 2018. A total of 866 heads of households residing in the rural field practice area of the institute were included in the study, while migrants as well as those unwilling to participate in the study were excluded. A semi-structured, pre-tested questionnaire was used to collect the data. House to house surveys were conducted and heads of the families were interviewed after taking their written informed consent. In absence of head of the family, any adult member who could provide the desired information in a reliable manner was interviewed. Data was collected pertaining their demographic characteristics, HSB and reasons for not using any particular system or a health care facility. The data was entered in the Microsoft excel sheet and the analysis was done using SPSS version 22. Results were expressed in the form of tables and pie diagrams. $\mathrm{P}$ values of 0.05 or less, were considered significant.

\section{RESULTS}

A total of 866 heads of families were enrolled in the study, which included $849(98.03 \%)$ males and 17 $(01.96 \%)$ females, showing male dominance in the rural society, as almost all the households were headed by the males. The study further brings out that majority of them i.e., $302(34.87 \%)$ belonged to $46-54$ years age group, 323 (37.29) were educated up to high school. 309 $(35.68 \%)$ were involved in agricultural work while 343 $(39.60 \%)$ of them were having monthly family income between Rs. 5000 to 10000 . Further, most of the families i.e., $581(67.09 \%)$ were of joint type in nature (Table 1).

Table 1: Socio-demographic characteristics of study participants $(n=866)$.

\begin{tabular}{|c|c|c|}
\hline Characteristics & Frequency & $\%$ \\
\hline \multicolumn{3}{|l|}{ Age group (in years) } \\
\hline$<35$ & 79 & 09.12 \\
\hline $36-45$ & 255 & 29.44 \\
\hline $46-54$ & 302 & 34.87 \\
\hline$>55$ & 230 & 26.55 \\
\hline \multicolumn{3}{|l|}{ Education level } \\
\hline Illiterate & 17 & 01.96 \\
\hline Primary & 189 & 21.82 \\
\hline High school & 323 & 37.29 \\
\hline Higher secondary & 139 & 16.05 \\
\hline Diploma courses & 112 & 12.93 \\
\hline Graduate and above & 86 & 09.93 \\
\hline \multicolumn{3}{|l|}{ Occupation } \\
\hline Unskilled labourer & 88 & 10.16 \\
\hline Skilled labourers & 182 & 21.06 \\
\hline Farmers & 309 & 35.68 \\
\hline Private service & 73 & 08.42 \\
\hline Government service & 67 & 07.73 \\
\hline Unemployed & 147 & 16.97 \\
\hline \multicolumn{3}{|l|}{ Gender } \\
\hline Male & 849 & 98.03 \\
\hline Female & 17 & 01.96 \\
\hline \multicolumn{3}{|c|}{ Total income of the family in rupees } \\
\hline$<5000$ & 137 & 15.81 \\
\hline $5000-10,000$ & 343 & 39.60 \\
\hline $10,000-20,000$ & 237 & 27.36 \\
\hline$>20,000$ & 149 & 17.2 \\
\hline \multicolumn{3}{|l|}{ Type of families } \\
\hline Nuclear & 285 & 32.90 \\
\hline Joint & 581 & 67.09 \\
\hline
\end{tabular}

The study brings out that majority $56.4 \%$ of study participants preferred public health care facilities for their illnesses, while $33.37 \%$ of them reported to Ayurveda. 
Remaining $11.08 \%$, subjects preferred other systems of AYUSH. The study further brings out that majority, $48.15 \%$ of the study population preferred to go to government health care facilities while remaining $31.29 \%$ and $20.55 \%$ preferred to visit private practitioners and pharmacies respectively (Table 2).

Table 2: Distribution of study subjects according to preference of health care system $(n=688)$.

\begin{tabular}{|lll|}
\hline $\begin{array}{l}\text { Preferred system of } \\
\text { medicine }\end{array}$ & Frequency & $\%$ \\
\hline Allopath & 481 & 55.54 \\
\hline Ayurveda & 289 & 33.37 \\
\hline Homeopath & 64 & 07.39 \\
\hline Others & 32 & 03.69 \\
\hline \multicolumn{2}{|l|}{ Type of health care facility preferred } \\
\hline Government hospitals & 417 & 48.15 \\
\hline Private practitioners & 271 & 31.29 \\
\hline Over the counter (pharmacy) & 178 & 20.55 \\
\hline
\end{tabular}

\begin{tabular}{|l|l|}
\hline \\
" Fever
\end{tabular}

Figure 1: Morbidity profile of participants under study $(n=866) *$.

*: Multiple responses.

The study reveals febrile illnesses as the commonest cause $87.87 \%$ of visit to various health care facilities among the study participants, followed by chronic cough $22.17 \%$, gastro-intestinal problems $21.82 \%$, skin problems $20.90 \%$, hypertension $20.43 \%$, arthritis $16.51 \%$ and diabetes mellitus $11.31 \%$. Other morbidities which required health care interventions, included cataract, hearing problems, ischemic heart disease, tuberculosis, alcohol liver diseases etc (Figure 1).

Present study brings out awareness on prevalent health insurance schemes in their area and status of subscription among the study subjects. It was a pleasant finding to know that more than half $56.46 \%$ of the study participants were aware about the various available government and private health insurance schemes. However, not surprisingly, only $34.97 \%$ of these who were aware of these health insurance schemes had subscribed to some health insurance policies. Further, out of those who had subscribed to insurance policies, majority of them $95.90 \%$ had opted for government health insurance schemes, while a very small fraction $04.10 \%$ had some private health insurance coverage (Table 3).

Table 3: Awareness on health insurance policies and coverage among study subjects $(n=866)$.

\begin{tabular}{|c|c|c|}
\hline & No. & $\%$ \\
\hline \multicolumn{3}{|c|}{ Awareness $(\mathrm{n}=866)$} \\
\hline Yes & 489 & 56.46 \\
\hline No & 377 & 43.54 \\
\hline \multicolumn{3}{|c|}{ Subscription among the aware $(n=489)$} \\
\hline Yes & 171 & 34.97 \\
\hline No & 318 & 65.03 \\
\hline \multicolumn{3}{|c|}{ Type of health insurance $(n=171)$} \\
\hline Government & 164 & 95.90 \\
\hline Private & 07 & 04.10 \\
\hline
\end{tabular}

The study also brings out the determinants of HSB and the reasons for preference of visiting a particular health care system i.e., government, private or any other i.e., pharmacy etc. The study reveals low cost of treatment as the most important determinant of HSB, while convenience of approach, quality of health care services, personal attention by the doctor, waiting time, consultation fee and life threatening emergencies were other important causes which determined the process of decision making in visiting a particular health care facility.

Table 4: Determinants of health seeking behaviour among study participants $(n=866) *$.

\begin{tabular}{|c|c|c|c|c|c|c|c|c|}
\hline \multirow{2}{*}{ S. No. } & \multirow{2}{*}{ Reason } & \multicolumn{2}{|c|}{ Government $(n=417)$} & \multicolumn{2}{|c|}{ Private $(n=254)$} & \multicolumn{2}{|c|}{ Others $(n=195)$} & \multirow{2}{*}{$\begin{array}{l}\text { P. } \\
\text { value }\end{array}$} \\
\hline & & No. & $\%$ & No. & $\%$ & No. & $\%$ & \\
\hline 1. & Cost of treatment & 177 & 42.44 & 72 & 28.34 & 106 & 54.35 & 0.001 \\
\hline 2. & Convenience of approach & 137 & 32.85 & 177 & 69.66 & 86 & 44.10 & 0.001 \\
\hline 3. & Quality of services & 91 & 21.82 & 189 & 74.40 & 104 & 53.33 & 0.001 \\
\hline 4. & Personal attention & 64 & 15.34 & 197 & 77.55 & 66 & 33.84 & 0.001 \\
\hline 5. & Waiting time & 88 & 21.10 & 203 & 79.92 & 106 & 54.35 & 0.001 \\
\hline 6. & Life threatening emergencies & 341 & 81.77 & 82 & 32.28 & 57 & 29.23 & 0.001 \\
\hline 7. & Consultation fee & 211 & 50.59 & 133 & 52.36 & 111 & 56.92 & $>0.05$ \\
\hline 8. & Other reasons & 93 & 22.30 & 104 & 40.94 & 55 & 28.20 & $>0.05$ \\
\hline
\end{tabular}

\footnotetext{
*: Multiple responses.
} 
All the reasons for choosing a government or private health care facility were found to be statistically significant from serial number 1-6, while the reason of consultation fee (serial 7) was not found to be a significant (Table 4).

\section{DISCUSSION}

Health is a fundamental right of every human being. India is committed to provide universal health coverage to all its citizens by 2030, though its realization by the given time line still seems to have many challenges, which include desired funding and availability of trained manpower. Studies also bring out gross under-utilization of the health services available in public sector, while on the other hand, private sector has been steadily growing as it meets the expectations of the common people and focuses mainly on "felt needs" of the local community. ${ }^{8}$ The concept of 'HSB' is an important tool for exploring and understanding patient preferences for variety of health conditions and the factors which influence their process of decision making which may include age, gender, social status, types of illness, access to services, perceived quality of services, economic status etc. ${ }^{9}$

Present study brings out male dominance among the study population, as almost all $98.03 \%$ the households were headed by males. Education level of majority $77.12 \%$ of them was higher secondary and below, one third of them $35.68 \%$ were involved in agricultural work while $39.60 \%$ were having monthly family income between Rs. 5000-10000. Similar results have also been reported by Chauhan et al, in their study in a coastal area of Villupuram district in Tamil Nadu and Kumar et al in their study in Varanasi (Uttar Pradesh). ${ }^{10,11}$

Present study reveals preference for public health care facilities $48.15 \%$ over private health care sector $31.29 \%$, among the participants. The study also brings out Allopath as the most preferred system (55.54\%), followed by Ayurveda (33.37\%). Similar findings have been brought out by Kumar et al, who in their study in Varanasi (Uttar Pradesh) found that $74 \%$ of the respondents sought treatment from government hospitals followed by pharmacy $(20.9 \%)$ and private practitioner $(17.4 \%)$. Their study also brought out Allopathic as the most preferred $(77.9 \%)$ system among respondents, while Ayurveda and Homeopath systems were preferred by $13.8 \%$ and $8.3 \%$ respectively. In another study by Sharma et al, in Shimla $81.4 \%$ of the respondents preferred Allopath while $11.3 \%$ preferred Ayurveda system. Further, Patil et al, in their study in a slum in Mumbai found much higher rate $85.5 \%$ of preference for government hospitals, while only $14 \%$ respondents preferred private hospitals. High preference of utilisation of government health care services has also been reported by Sachdev et al in their study in Rajasthan and Aggarwal et al in Uttar Pradesh. ${ }^{11-15}$
Our study brings out fever as the most common cause $87.87 \%$ for seeking health care, followed by chronic cough $(22.17 \%)$, gastro-intestinal problems (21.82\%), skin problems $(20.90 \%)$, hypertension $(20.43 \%)$, arthritis $(16.51 \%)$ and diabetes $(11.31 \%)$. Cataract, deafness, ischemic heart diseases, tuberculosis and alcohol liver diseases were other common disorders for which respondents sought consultation from heath care providers (Figure 1). Similar findings have been reported by Chauhan et al, who in their study reported febrile illness $(39.5 \%)$, pain $(20.8 \%)$, respiratory problems $(8.4 \%)$, diarrhoea $(8.6 \%)$, gastrointestinal problems $(5.2 \%)$, diabetes and road traffic accidents as the common causes for seeking health care services. However, Kumar et al, in their study reported musculoskeletal problems as the most common $(56.5 \%)$ cause for seeking health care, followed by hypertension $(34.1 \%)$, cataract or other eye related problems $(23.1 \%)$ and diabetes $(6.7 \%)$ etc., while Patil et al, in their study reported ARI as the most common disease $(38.0 \%)$, for seeking health care, followed by tuberculosis $(30.75 \%)$, vector borne diseases like malaria and dengue, hypertension and diabetes. ${ }^{10-11,13}$

Present study brings out that more than half $(56.46 \%)$ of the study participants were aware of various available government and private health insurance schemes. However, only $19.74 \%$ of the respondents had insurance coverage, while most of them $(95.8 \%)$ had subscribed to government health insurance schemes. Netra et al in their study at Davangere (Karnataka), reported much higher $(65.7 \%)$ level of awareness among the respondents, while $45.5 \%$ of them had insurance coverage, $90.5 \%$ of them under government health insurance schemes i.e., Yeshasvini co-operative farmers' health scheme, RSBY, Vajpayee Arogya Bhagya and ESI etc. Further, Indumathi et al, in their study in rural population of Bangalore (Karnataka) also brought out a high level $(75.7 \%)$ of awareness on health insurance schemes, while $66.9 \%$ of them were existing subscribers. In another study by Bansal et al, in Fatehgarh, Uttar Pradesh, among rural population, low levels $(43.4 \%)$ of awareness were reported. $^{16-18}$

Present study brings out cost of treatment, convenience of approach, quality of services, personal attention, waiting time, life threatening emergencies and consultation fee as the main determinants for preferring a particular health care facility i.e., public or private sector health care facility. All above reasons for choosing a government or private health care facility were also found to be statistically significant ( $p$ value $<0.001$ ), except the "consultation fee" which did not play a significant role in the process of decision making ( $p$ value $>0.05$ ) to visit any particular health facility.

Similar findings have been reported by Chauhan et al, in their study where "cost of treatment, convenience of access, emergency services" were found to be statistically significant causes for visiting a health care facility. In another study in rural parts of Wolaita Zone, Southern 
Ethiopia, by Falaha et al, health care seeking behaviour of the participants was reported to be unsatisfactory as half of them did not visit the health facility during their illness, while "family support during illness, knowledge when to visit health facility and accessibility to health facility" were found to be major predictors of health care seeking behaviour among respondents. In another study by Moe et al, in Myanmar, HSB was not found to be associated with gender, ethnicity or religion. However, $6.8 \%$ of the participants who are below poverty line took treatment while $14.8 \%$ of those who were above poverty line took treatment for current illness, while this difference was also found to be statistically significant. Further, Lubega et al, in their study in Uganda, brought out that "conformity to masculinity and cost of care" were the most influencing factors of men's "poor" HSB with p-values $<0.0001$; while socio-demographic factors did not indicate significant influence on men's health seeking behavior. ${ }^{19-21}$

\section{CONCLUSION}

Health care seeking behaviour is a complex and dynamic process. Understanding its determinants in a community is important to know planning National health policies and design appropriate local interventional strategies. This becomes even more relevant in rural areas in India, where majority of people are not "well informed" of available public health care options while poverty becomes a major barrier to afford "good quality" health care in a private sector. Quality of services , convenience of approach, lack of personal attention and long waiting time have been found to be significant barriers for seeking health care in public sector, which require to be addressed. The level of awareness and frequency of subscription to various available health insurance schemes was also found to be sub-optimal among the participants, which can be alleviated by organizing awareness campaigns and setting up registration centres in rural areas.

\section{Strengths}

The present study has made a sincere attempt to bring out health seeking behavior of rural population in southern part of the country and the various factors which influence the process of decision making as regards to which type of system and which health care facility to be used for their illnesses. We focused on another important but often neglected aspect of health care- the health insurance, and tried to assess its level of awareness and as well as its subscription rates among the study population. An effort was also made to take large sample size to achieve generalizability of the findings.

\section{Limitations}

The present study had the limitation which is inherent to all cross sectional studies i.e., lack of follow up and hence we could not analyze their "health care seeking behaviour" over a prolonged period of time. In addition recall bias as well as social desirability bias may not be ruled out, as many respondents might be hesitant to admit as to when, which and why they visited a traditional practitioner, government healthcare facility or a private practitioner.

\section{ACKNOWLEDGEMENTS}

Authors would like to sincerely thank all the heads of families for their consent to be a participant in this research, as well as all the para-medical staff for their support in the conduct of the study.

\section{Funding: No funding sources}

Conflict of interest: None declared

Ethical approval: The study was approved by the Institutional Ethics Committee

\section{REFERENCES}

1. Conner M, Sparks P. The theory of planned behaviour and health behaviors in predicting health behaviors: Research and Practice with Social Cognition Models. In: Conner M, Norman P, eds. Predicting health behaviour: Research and practice with social cognition models. Maidenhead, BRK, England: Open University Press; 2019: 121-162.

2. Ministry of AYUSH. Government of India. Available at: http://ayush.gov.in/. Accessed on 4 September 2019.

3. Wikipedia. Health Care in India. Available at: https://en.wikipedia.org/wiki /Healthcare_in India. Accessed on 4 September 2019.

4. Kastor A, Mohanty SK. Disease-specific out-ofpocket and catastrophic health expenditure on hospitalization in India: Do Indian households face distress health financing. Plos One. 2018;13(5):e0196106.

5. National Health Accounts Estimates for India, 2018. Available at: https://mohfw.gov.in/sites/default/file s/NHA_Estimates_Report_2015-16.pdf. Accessed on 4 September 2019.

6. Bharat A. Pradhan Mantri Jan Arogya Yojana. Available at: https://www.pmjay .gov.in/. Accessed on 4 September 2019.

7. Basak M, Chaudhuri SB, Ishore K, Bhattacherjee S, Das DK. Pattern and trend of morbidity in the infectious disease ward of North Bengal Medical College and Hospital. J Clin Diagn Res. 2015;9(11):LC01-4.

8. Ramana BV, Gayatri D, Kumari RP. A study to assess the utilization of health care services among fishermen communities in urban slums of Visakhapatnam city: a cross sectional study. Int J Community Med Public Health. 2017;4(10):383541.

9. Abubakar A, Van Baar A, Fischer R, Bomu G, Gona JK, Newton CR. Socio-cultural determinants 
of health-seeking behaviour on the Kenyan coast: a qualitative study. Plos One. 2013;8(11):e71998.

10. Chauhan RC, Kandan M, Purty AJ, Samuel A, Singh Z. Determinants of health care seeking behavior among rural population of a coastal area in South India. Int J Scientific Report. 2015;1(1):11822.

11. Kumar D, Kumari R, Shankar H. Health status and health seeking behaviour of rural geriatric population of Varanasi district, India. Int J Med Sci Public Health. 2015;4(12):1711-4.

12. Sharma D, Mazta SR, Parashar A. Morbidity pattern and health seeking behaviour of aged population residing in Shimla hills of north India. J Fam Med Prim Care. 2013;2(2):188-93.

13. Patil SP, Parbhankar SS, Gokhe SB, Shelke PS, Singh RD. Study of health seeking behavior and its determinants among attendees of urban health center, Dharavi, Mumbai, India. Int J Community Med Public Health. 2016;3(7):1856-61.

14. Sachdev B. Perspectives on health, health needs and health care services among select nomad tribal populations of Rajasthan, India. Antrocom Online J Anthropol. 2012;8(1):73-81.

15. Aggarwal P, Kandpal SD, Negi KS, Gupta P. Health seeking behaviour for RTIs/ STIs: study of a rural community in Dehradun. Health and Population: Perspectives and Issues. 2009;32(2):66-72.

16. Netra G, Rao BAV. A study on awareness, coverage and willingness to avail health insurance among the residents of a rural area in Central Karnataka. Nat J Community Med. 2019;10(4):190-6.

17. Indumathi K, Saba IH, Gopi A, Subramanian M. Awareness of health insurance in a rural population of Bangalore, India. Int J Med Sci Public Health. 2016;5(10):2162-7.

18. Bansal A, Goel S, Singh A, Singh AA, Goel AK, Naik SM, et al. A community-based study to assess the awareness of health insurance among rural Northern Indian population. Int J Health System Disaster Manag. 2015;3(1):41-3.

19. Falaha T, Worku A, Meskele M, Facha W. Health Care Seeking Behaviour of Elderly People in Rural Part of Wolaita Zone, Southern Ethiopia. Health Sci J. 2016;10:4.

20. Moe S, Tha K, Naing DKS, Htike MMT. Health seeking behaviour of elderly in Myanmar. Int $\mathbf{J}$ Collaborative Research on Internal Medicine \& Public Health. 2012;4(8):1538-44.

21. Lubega GN, Musinguzi B, Omiel P, Tumuhe JL. Determinants of health seeking behaviour among men in Luwero District. J Educ Res Behavior Sci. 2015;4(2):037-54.

Cite this article as: Kumar H, Kapinakadu S, Anil M. Health seeking behaviour and its determinants among rural population: a cross sectional study in South India. Int J Community Med Public Health 2019;6:4944-9. 